\title{
Utilizing Educational Robotics for Environmental Empathy Cultivation in Primary Schools
}

\author{
Dimitris Ziouzios $^{1, *(D)}$, Dimitrios Rammos ${ }^{2}$, Tharrenos Bratitsis ${ }^{2} \mathbb{D}$ and Minas Dasygenis ${ }^{1}$ (D) \\ 1 Department of Electrical \& Computer Engineering, Faculty of Engineering, University of Western Macedonia, \\ 50100 Kozani, Greece; mdasygenis@uowm.gr \\ 2 Department of Early Childhood Education, School of Humanities and Social Sciences, University of Western \\ Macedonia, 53100 Florina, Greece; drammos@uowm.gr (D.R.); bratitsis@uowm.gr (T.B.) \\ * Correspondence: dziouzios@uowm.gr; Tel.: +30-698-760-4110
}

Citation: Ziouzios, D.; Rammos, D.; Bratitsis, T.; Dasygenis, M. Utilizing Educational Robotics for Environmental Empathy Cultivation in Primary Schools. Electronics 2021, 10, 2389. https://doi.org/10.3390/ electronics10192389

Academic Editor: Ngai-Man (Man) Cheung

Received: 9 September 2021

Accepted: 27 September 2021

Published: 30 September 2021

Publisher's Note: MDPI stays neutral with regard to jurisdictional claims in published maps and institutional affiliations.

Copyright: (c) 2021 by the authors. Licensee MDPI, Basel, Switzerland. This article is an open access article distributed under the terms and conditions of the Creative Commons Attribution (CC BY) license (https:/ / creativecommons.org/licenses/by/ $4.0 /)$.

\begin{abstract}
The fostering of empathy among primary school students is an important goal because it enhances the improvement of behavior and the development of positive social contacts. Empathy can contribute to understanding and supporting others' needs. In most cases, empathy in young children is developed through listening to sad stories, experienced first-hand by others. In the educational scenario presented in this article, the dramatic effects of climate change were conveyed to the pupils through a message said to originate from the future, delivered by an educational robot. The message was expressed by a peer living in Iran in 2050. In addition to delivering the message, the robot called on children to prevent climate change from rapidly worsening by changing their own way of thinking and attitudes. Thus, students called upon a formulated educational problem to understand and handle through their own emotional and cognitive performance through the robot's storytelling. This performance was intensely affected by empathy towards the Iranian peer's difficult personal living conditions. The research focused on measuring the evidence of empathy development. Additionally, the design and implementation aspects of the robot are presented, utilizing the implemented teaching intervention as means of demonstrating the innovative nature of the robot.
\end{abstract}

Keywords: empathy; climate change; educational robot; sustainability; teaching scenario; primary education

\section{Introduction}

Educational robotics is increasingly being exploited by primary school teachers, especially in projects aimed at developing 21st century skills [1,2]. Empathy is one such kind of skill which is deemed to crucially beneficial for students since it helps students better understand people's social behavior and shape their own attitudes towards different social issues [3,4]. Many studies highlight the contribution of empathy to the cognitive and behavioral development of young students within school and family environments [5,6].

Various factors related to other people's behavior or changes in the social environment may cause empathy development in children. In most cases, the degree of development is greater when descriptions of unpleasant incidents or difficulties faced by someone are processed [7,8]. Thus, addressing a difficulty experienced by one or more people raises the reflection and expression of emotions in a safe and secure personal context. In an educational context, these kinds of descriptions and stories from others could be presented as part of teaching scenarios to develop empathy for major problems worldwide. This article presents an educational scenario aimed at developing empathy for the current problem of climate change and global warming. Climate action is one of the 17 UNESCOs Sustainable Development Goals, promoted in young people's education in accordance with European Union directives $[9,10]$.

Novel tools to develop empathy in pupils are always welcomed by the educational community, especially if they utilize modern technologies and capture everyone's attention. 
Here, we present our contribution to this field. Concerning the most appropriate way to measure empathy in children, there are ongoing discussions from various esteemed researchers [11-13]. Specifically, the accuracy of research measuring tools is limited in children, especially younger ones, due to the influence from their environment and their cautious attitude towards scientific measurement procedures in general [11]. For this reason, systematic observation of student's performance during project activities is the strategy proposed in this article for assessing the development of empathy. This observation was followed by filling in an evaluation rubric, developed by the members of the research team.

The paper is structured as follows: initially, the notion of empathy and its significance within education and social interaction is discussed; then, the utilization of robots in education is examined, leading to the proposed implementation of the EI-EDUROBOT; after that, a case study in which the robot was utilized for the facilitation of environmental and social empathy is presented, showcasing the unique functionalities of the robot's design, before the concluding discussion.

\section{Empathy: A Very Important and Useful Aspect of Social Life}

Empathy is a set of processes which affect and shape the way people comprehend other people's behavior. Fostering empathy between members of a society could be directly reflected in every aspect of social life. According to Hoffman [14], empathy is " ... the spark of human concern for others, the glue that makes social life possible" (p. 3). Research findings consistently demonstrate that empathy contributes to developing positive and supportive relationships and to understanding and supporting others' needs [15]. Empathy is valuable for all age groups and all types of societies. Consequently, the development of empathy among young people can enhance the well-being of the whole society [13].

Although there is no unanimity among researchers as to the definition and the elements that constitute empathy, there are three distinct strands which emerge in most empirical studies $[13,16,17]$. These are empathic resonance, empathic reasoning and empathic response.

- Empathic resonance, which comprises the emotional aspect of empathy, is the impulsive mirroring of another's emotional experiences, such as sorrow or joy;

- Empathic reasoning, which comprises the cognitive element of empathy, is a conscious perception whereby an individual imagines themself 'in the other's shoes' while taking several environment considerations into account;

- Empathic response, which comprises the behavioral aspect of empathy, is an internal cognitive and inspirational process that motivates an individual to act on behalf of the other's needs.

The empathic process begins with an emotional resonance between two individuals, followed by the empathizer taking perspective on the other's situation, and conclude on a supportive behavior [18]. Empathy, as a whole, is considered one of the most seminal social-emotional competencies [19].

\section{Empathy in Children}

Empathy in childhood is particularly important and has therefore piqued the interest of researchers. A typical example was the research of the Department of Psychology of the University of Chicago in September 2013, published in the journal Frontiers in Human Neuroscience, according to which children aged from six to twelve years old had the ability to feel compassion for people who felt pain [20]. More specifically, it appeared that additional aspects of the brain were activated when they were confronted with a person who was deliberately harmed by another. These aspects significantly included the area concerning moral reasoning of the brain. Moral reasoning, however, is also influenced by the way parents behave towards their children, because children learn and enhance their emotional world through interactions within their family environment $[20,21]$. 
On the other hand, school has always been a crucial formative factor of a child's emotional world. Therefore, empathy should be part of the pedagogical process because cultivating the psychoemotional culture of the individual is an important objective of education [22].

The learning process is particularly influenced by the emotions experienced by the child. Educators must be able to attract and understand their pupils in order to be able to serve their mental and learning needs. In each school class, there are pupils with different cognitive and emotional backgrounds, which makes the role of the teacher complex but crucial.

Goleman [23] argued that teachers are able to develop the emotional intelligence of students. They should therefore plan appropriate activities as part of a broader strategy. In this case, the teacher's initiative can cover the absence of emotional intelligence programs in the curriculum. According to the majority of relevant surveys, the development of emotional skills such as empathy is more easily achieved in the early years of a child's life, specifically at the age of $6-8$ years $[13,17]$. Of course, the formation of empathy is evolutionary and continues in older ages. Primary school age, however, is when children's emotions are considered to be the most malleable and decisive.

Some other studies highlight the importance of having teachers with a high empathy level [24,25]. This leads to appropriate learning environments where teachers seek to cooperate and cultivate a friendly learning climate. When this is achieved, it is very likely that the needs of pupils are understood and properly taken into account. This, in turn, can lead to conflict resolution and the formation of a collaborative climate. The latter guarantees the creative and efficient work of children in all kinds of teaching activities. This develops a high degree of empathy among children, which enhances the implementation of demanding educational scenarios.

In conclusion, as Goleman [23] says, students who have experienced emotional education appear to perform better and not adopt delinquent behavior. In addition, they acquire skills that will help them in their later school years and adulthood. Empathy helps to understand the world and to take initiatives to improve the lives of all people. In this study, students were guided to understand the issue of climate change by listening to the personal problems experienced by a peer in 2050 .

\section{Utilizing Robots in Education}

The use of robots in education is not a new idea. Starting from the 1980s, mainly though the Logo programming language, it has been based on constructivism and constructionism theories [26]. Educational robotics (ERs), in general, is the teaching method where robots are used by students usually under the guidance of a teacher [27]. Today, the use of robots in classrooms starts from the early ages. Jung and Won [28] systematically studied the literature and recorded the trends in educational robotics used as tools for STEAM education and other disciplinary areas, involving children aged 4 to 13 years old. Toh et al. [29] studied the literature and focused on the impact of robots on young children and education.

Nowadays, there are many robots utilized in educational contexts, starting from the age of 4. Most of them focus on disciplines which fall under the sciences area, when examined in the typical education context. The robot presented in this paper, named Emotional Intelligence Educational Robot (EI-EDUROBOT), can be utilized by students from the age of 4 and over without limits.

\subsection{The Design Principles and Idea of the EI-EDUROBOT}

The research team decided to design a new robotic system for the needs identified for empathy training in school settings. Prior to that, an extensive literature review was carried out, leading to the accumulation of 57 papers which were related to empathy, educational robotics and young age groups (4-9 years old). Regarding the content of the studies is out of the scope of this paper, although it is important to mention that no approach such as the 
one presented in this paper exists in the literature (focusing on environmental and social empathy in an interconnected manner).

For the needs of this paper, the type of robotic constructs was examined. Overall, there are three main categories of such constructs: floor roamers, humanoid or animal-like robots, and complex constructs. The first category refers to simple programmable robotic devices which are designed for moving on a simple surface (e.g., the floor or a table). The programming of such devices merely includes direction commands (e.g., forward, backward, left, right) with a predefined or varying step. A representative example of this category is BeeBot, a bee-like robot which can only receive directional commands (up to 44) and incorporates movements of $15 \mathrm{~cm}$ lengths or $90^{\circ}$ turns. The concept of utilizing this robot involves printed floor mats. Depending on the pictures on the mats, various teaching activities can be designed and contextualized. Other examples of robots in this category are BlueBot, Gigo first coding, Edison and Bottley. All of them are more appropriate for younger ages. Some of them (e.g., ProBot, which is a car-like robot) also incorporate touch sensors so that they can identify obstacles when moving.

The second category is that of humanoid robots, or ones which have the appearance of some life form. One example is the PLEO robot, a dinosaur-like robot which has been widely used for training social skills, because it can interact with a child in a social manner. It replicates behaviors based on fundamental feelings (e.g., fear, affection). Another example is Alpha 1S Pro, a humanoid robot which incorporated several servomotors and can execute various movements with very high precision and balance. It can also transmit pre-recorded audio files which are synchronized with the movements of the robot. Interaction with this robot is rather minimal and it can be utilized as a programmable device for solving realistic spatial problems. More sophisticated and much more expensive examples in this category are the NAO and the Pepper robots. Both are humanoid and they incorporate a large set of sensors which allows more realistic interaction with a person. NAO is a "close-to-real" humanoid robot which replicates physical movement and can also interact with a person with sound triggers (incorporating sound recognition). Pepper incorporates a screen on its chest for displaying multimedia content and can also interact via audio. Both are very expensive solutions and have been mainly used in controlled laboratory environments (NAO) or for other social activities (e.g., Pepper has been used as a guide in exhibitions or as a welcoming agent in airports).

The third category refers to robotic solutions which require some sort of construction that integrates sensors and/or motors. Probably the most known devices of this category are Lego sets (WeDo, EV3 and Spike). The kits provide structural elements such as building blocks, sensors (color, distance, infrared, tilt, etc.) and motors in order to create interactive constructs which can also be programmed to react to the inputs of the sensors. Depending on the complexity of the kits, they can be used by children of various age groups (e.g., from 7 to 18 years old). Usually, these robots do not have the ability to incorporate multimedia material in a native manner.

Considering all the aforementioned options, the research groups reached the conclusion that none of them would meet the needs of the designed studies. They all appeared to have several advantages and disadvantages. For example, the roamers are easy to program but do not actually interact with the children. The humanoid robots are more capable of interaction, but they are either too expensive (e.g., NAO) or they have limited interaction capabilities (Alpha 1S Pro). Other robots such as PLEO are designed for very specific tasks and have limited or no programming potential; thus, they are unfit for other types of educational activities. The last category requires building and programming block-based constructs which involve more complex skills (e.g., fine-motor skills), are more time consuming (due to the need to design and implement the construction), and have limited interactivity.

Thus, a strategic decision was made to design a new robot based on the review of the state of the art. Considering the target group (young students), the robot was designed in a humanoid form, incorporating a head, hands and movement capabilities. Taking 
into account safety issues, the robot incorporated wheels instead of legs, so as to be more sturdy and secure for both the children and itself. Various sensors were incorporated for that matter (see Section 4.2). The research team focused mainly on the interactivity of the robot with children. Consequently, several sensors were attached to the robot's body, which allowed interaction via touching. The face of the robot was selected to be a touch screen, allowing the robot to present multimedia material of any kind but also provide an additional interaction method (via the touch screen). Additionally, a camera, a microphone and speakers were incorporated to the robot which, with its various connectivity capabilities (Wi-Fi and Bluetooth), would allow free-form interaction with another human peer (e.g., a teacher or a researcher) via the robot in a realistic and free manner. For example, an adult with a plain headset would be able to carry out free-form and real-time verbal interaction with a child by listening through its microphone and talking through its speakers. This would be totally transparent for the child, because they would perceive that the interaction occurs with the robot only. These interactivity capabilities combined in a single device are not met in any of the existing solutions in the market.

All these elements were considered for designing the robot. Additionally, an attempt was made to keep the cost as low as possible while incorporating functionalities which can be seen in more sophisticated robots in the market (e.g., NAO, which costs over 10 times more than the EI-EDUROBOT). Lastly, the design of the EI-EDUROBOT had to allow expandability in both programming and mechanical aspects, enabling it to be very versatile and adaptable to any possible teaching interventions. The next section briefly presents the electromechanical design of the robot.

\subsection{Technical Aspects of EI-EDUROBOT}

EI-EDUROBOT was developed in the base of Open-Source Software and Open Hardware, where the research community and anyone with basic programming knowledge will be able to develop it further. With this philosophy, the robot was designed in-house in a 3D CAD software and manufactured with our 3D printer, utilizing the fused deposition modeling (FDM) technique. As for the electronic and mechanical systems, we followed the COTS (components off the shelf) principle for fast prototyping, and easily obtaining them from the market. As with any cyberphysical system such as our robot, it is a codesign process of hardware and software, which includes the robot's code, the online handling platform, and a mobile app.

All parts of the robot were constructed using polylactic acid (PLA) or polylactide, obtained from renewable and natural raw materials such as corn, because they are biodegradable and bioactive [30]. The frame of the robot was designed (Figure 1) with the aim of stability, endurance and protection, both for the robot itself and for the children, as the highest priorities, in order to achieve optimal distribution of its weight, resulting in stable and smooth movement. The interior of the robot is allocated to the electronic components. The robotic system had two arms with double hinges and were designed in such a way as to allow the user to add various components to the robot's hands, which were also designed and printed in FDM. The head could move on two axes: the horizontal axis (right-left) and the vertical axis (up-down). This design option allowed the robot to express the desired emotions (agreement, denial, irritability, etc.) with high precision due to the seven-inch touchscreen.

The 'brain' of the robot was based on a Raspberry Pi 4 model B with a high-performance 64-bit quad-core processor, with up to $4 \mathrm{~GB}$ of RAM, which supports dual-band 2.4/5.0 GHz wireless LAN and Bluetooth 5.0 and has dual-display support at resolutions up to $4 \mathrm{~K}$ via a pair of micro-HDMI ports. These specifications met the project's requirements, and due to the low cost and low energy usage, made it cost-effective. The use of Raspberry Pi gives huge possibilities to both manufacturers and users to customize various accessories. 


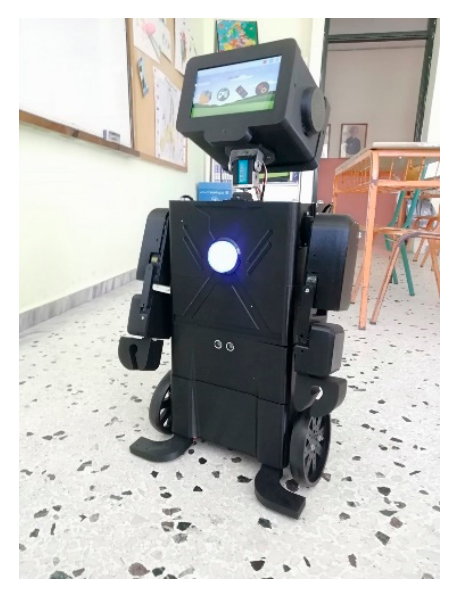

Figure 1. The EI-EDUROBOT.

The robot integrated a variety of sensors that can be divided into two major categories: (i) security-related, and (ii) operationally related. As for the first category, the robot incorporated ultrasonic sensors in the front and rear, which were activated when the robot moved. If an obstacle was detected, the robot stopped moving. Additionally, at the bottom (in front and behind the wheels), there were infrared (IR) sensors, so if the robot was placed at an elevated point, it stopped moving when it reached its edge (by detecting the corresponding gap). The second sensor category concerned the functions of the robot, where the educator could optionally make use of it, if they wished. Specifically, it had two pressure sensors in the hands (right-left), and a button on the chest, for which the usage was dependent on the loaded scenario, so the robot executed different commands. On the head, a thin membrane potentiometer was placed. Its resistance changed linearly from 100 to $10,000 \mathrm{Ohms}$ by simply pressing down on various places of the sensor strip, making it possible to calculate the pressure position on the strip with precision. This was critical for the proposed implementation because the robot could detect a touch on the head and react in response to the pressure. Each sensor could perform different tasks which depended on the script developer. Figure 2 presents a diagram of the sensors.

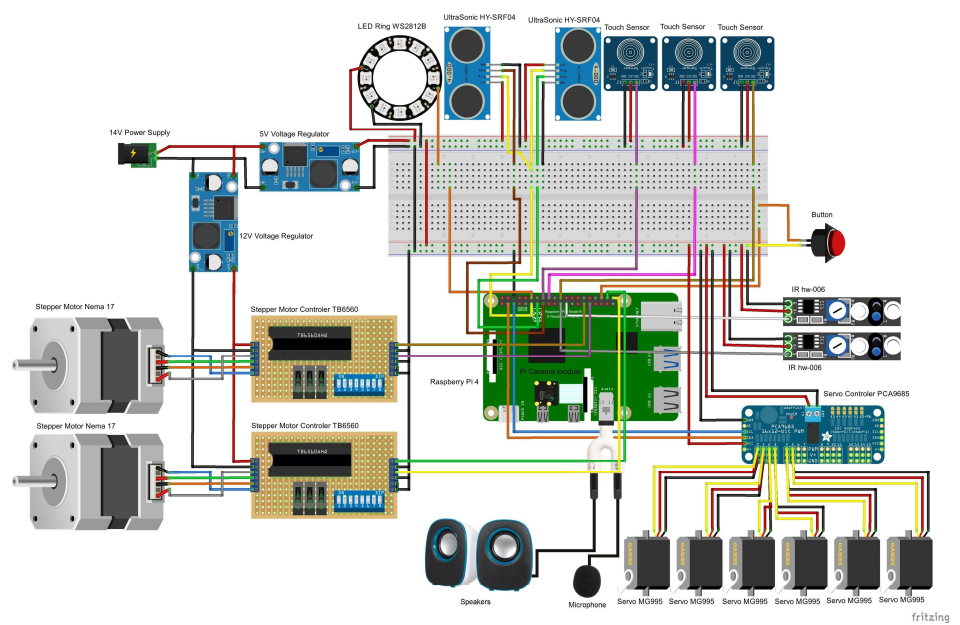

Figure 2. Diagram of the sensors.

For easier connection of the robot's sensors and motors, a printed circuit board (PCB) was developed as illustrated in Figure 3. Two TB6560 chips controlled the motors, while a PCA9685 16-Channel controlled the servos. The system's smooth operation was ensured by the employment of two voltage reducers, one at 12 volts and the other at 5 volts. 


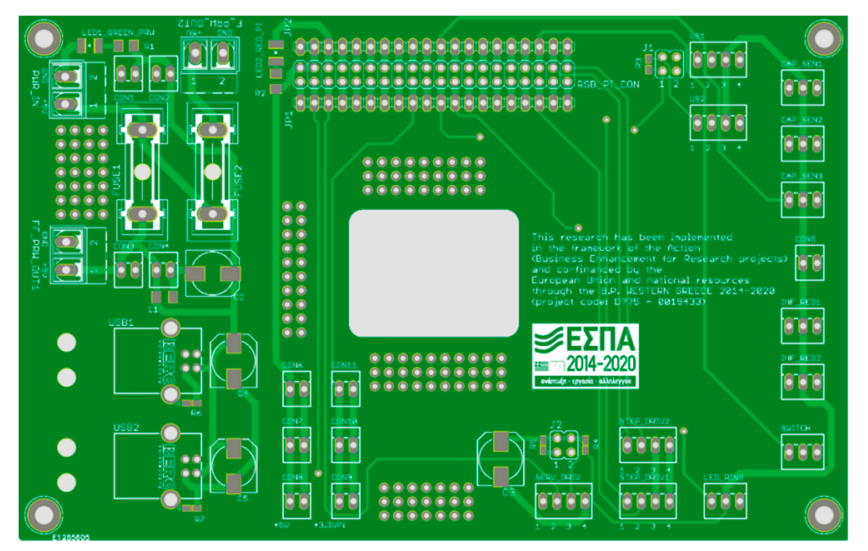

Figure 3. Printed circuit board of our robot.

Moreover, in terms of software, three basic tools have been developed for using the robot: (i) the robot user platform, (ii) the robot code, and (iii) the application for smartphones with the Android operating system. Through these tools, the trainer could utilize all the functions of the robot and even develop them further. Raspberry Pi controlled the Raspbian operating system (OS), a free OS based on Debian that is customized for the Raspberry Pi hardware. Python, a sophisticated and quick programming language, was utilized to control the robot and use all of its capabilities. Python is a user-friendly programming language in which anyone with basic knowledge of programming can develop a scenario. The robot's graphical user interface (GUI) was created using the PyQt toolkit, which is a Python add-on. The Python programming language was used to create various educational scenarios. Users with the required programming skills can use the Python programming language to create programs that control robot sensors and motors. The research team aspired for this platform to become a useful tool at the disposal of teachers who know basic programming concepts so that they can develop their own scenarios, depending on the needs they recognize.

An information system was designed to coordinate the transmission of information from the user's device to the robot in order to achieve communication between the user and the robot. The web application and the Rest API made up this information system. The MEAN architecture, which consisted of MongoDB, Express framework, Angular framework and NodeJS, was used to develop all aspects of the system. The advantages of the MEAN architecture include the fact that it is an open-source framework that can be used as a standalone solution in a complete application and that it includes extra frameworks, libraries, and reusable modules to speed up development. The system is highly scalable and maintenance-friendly thanks to these technologies. It is also feasible to create new applications that can support the system's capabilities by using JSON files for data transmission between the user, the API, and the robot.

The humanoid robot was controlled via an Android app by its operators. The app used the Rest API (application programming interface) to communicate directly with the robot and the (IS) information system and provide critical information about the robot's smooth movement and operation. Particularly, the Android application allowed the user to control the robot's legs, hands, and head directly, as well as execute a pre-configured script including a sequence of movement commands. This allows users to choose and execute an installed scenario of the robot. The Microsoft Xamarin framework was used to create the Android application, which was written in C\# and XAML. The robot communicated with the information system via the Wi-Fi protocol at predetermined intervals (polling). All data (including scenarios and movement-related information) were compressed and encrypted before the transmission process began. Lossless compression formats, such as PNG and WebP, were utilized for photos and movies. The robot used the asymmetric encryption algorithm RSA for encryption, which meant that even if the robot was stolen or communication was intercepted, malicious users would not be able to decrypt the data 
because they will not have access to the secret RSA key. The Android App was could very easily be used by teachers and students from the age of 4 years old.

\section{Education on Climate Change and Empathy}

Action on climate change is one of the timeliest goals for improving people's lives. According to scientists' data, climate change is expected to cause intolerable living conditions in the future [31]. In addition, problems in daily life of societies are expected to occur. The actions of people today directly affect climate change. Raising awareness and taking immediate action at all levels are, therefore, very crucial factors in preventing the phenomenon [32].

Even more important is the awareness of young people and children from their early school years. Therefore, raising awareness of climate change in students should be part of the broader goal of active citizenship and participation in social dialogue and decisionmaking.

The modern reality about the climate and predictions for its future development are complex issues with scientific implications. Thus, it is quite difficult for children to accurately understand how it affects their lives. In addition, the issue of climate change has political and economic implications that confuse and disorient the mind from the daily and immediate dimensions of the problem [31,32].

Perhaps the most effective method for children to process the issue in a meaningful and practical way is to develop empathy about the problems that climate change has created or is expected to create in people's lives in the future: to put themselves in their place, in other words, so that they understand their phobias and feelings [31].

In terms of teaching methodology, the implementation of an educational scenario aimed at developing empathy for climate change depends on many factors such as the age of children and their cognitive background. In addition, it depends on elements that will give originality and attractiveness, such as the possibility of using new technologies. The model of such an educational scenario is presented in this article.

\section{The Implemented Educational Scenario}

The specific educational scenario of utilizing the educational robot was designed to be carried out with elementary school students. The robot's programming presented an educational problem to the students through the projection of multimedia material on the screen located on its head. Solving the educational problem required interaction of the robot with the children. Therefore, the whole didactic approach was performed through the robot; the researchers were responsible for its programming. At the same time, the research team was able to determine and differentiate the flow of the scenario through a corresponding application for smart devices. At the research level, the members of the research team acted as observers, filling in observation rubrics on the topic of developing empathy in the students.

The learning strategy of the educational scenario combined the problem-solving method through STEAM activities. Problem-based learning (PBL) is a learning strategy in which complex problems from real life are utilized to promote student learning and to develop learning skills as opposed to the direct presentation of facts. Complementary to course content, PBL can promote the development of empathy. It can also provide opportunities for evaluating research materials, and for developing active citizenship [33]. PBL can be incorporated into any learning situation. The core thread is a real-world problem, which ensures relativity and increases children's interest.

Moreover, the problem should motivate students to seek out a deeper understanding of concepts. Additionally, they should be required to make reasoned decisions and to defend them, as well as express their feelings and relate them to these decisions.

On the other hand, STEAM teaching methodology reinforced the interdisciplinary approach of the educational problem, combining robotics with the scientific fields of meteorology, environment, mathematics and geography. For the needs of the scenario, the 
EI-EDUROBOT presented itself to the students as ENVIE S-50, a robot from the future. ENVIE S-50 had returned to 2021 from the distant 2050 in order to inform children about the climate conditions and to convey a message to them from a 12-year-old child, Reza, who lived in Iran in 2050.

The theoretical framework of the educational scenario concerned the causes of climate change and the greenhouse effect. Most of it was incorporated into the video messages presented to children through the robot's screen/face. This practically means that new knowledge was mainly delivered by the educational robot. The videos were divided into two categories: those addressed to the children by the robot itself, where information was presented and missions were assigned; and those in which Reza told his digital story to the children in the form of an animated hero, as shown in Figures 4 and 5.
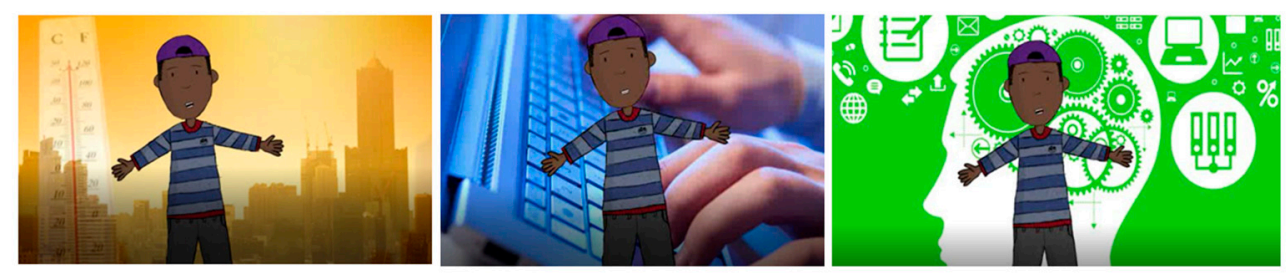

Figure 4. The image of Reza, as shown on the robot screen.

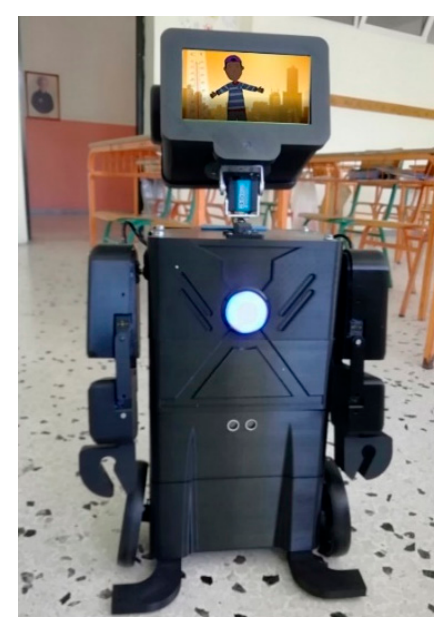

Figure 5. The scenario of Reza in a classroom.

Reza's message was far from pleasant, describing in detail the extremely difficult living conditions of Iran's inhabitants in 2050 due to overheating. These descriptions concerned his daily and school life as well as the government's actions to tackle the problem. In turn, the robot asked children to reflect on people's responsibilities in previous decades in terms of not caring and acting enough to prevent these negative developments. In addition, the children had to think and record the initiatives they intended to undertake themselves in their daily lives to prevent catastrophic climate change. This treaty actually created an «educational problem» which student were asked to solve by identifying changes in their personal perceptions and attitudes towards climate change (UNESCO/UNEP, 2011).

After the completion of the process and the proposed solutions on the educational problem, the robot reviewed the children's proposals through a new journey to 2050. This journey aimed the check whether the new way of thinking and attitudes of the children had had a prompt impact on future climate change. After that, the robot returned to 2021 to announce the findings of his observations to the children. In fact, the robot's ability to travel to and from the future was a unique opportunity for children to understand the power and impact of their decisions on the evolution of individual and social life.

Cumulatively, the educational scenario was implemented in five stages. In the first stage, the teacher referred to the concepts of sustainable development and climate change 
by highlighting the great importance given worldwide to the subject/problem through the projection of audiovisual material. Children's previous knowledge and thoughts on the subject were then illustrated in digital conceptual maps.

The second stage concerned the theoretical framework of the phenomenon of climate change which extends, cross-thematically, to the cognitive regions of natural sciences, mathematics, geography, language, and social and political education. The teacher presented scientific data and information on the causes of climate change and its present and future impacts on people's lives on a global scale. The whole teaching approach was theoretically integrated under the study of the United Nations' 17 Sustainable Development Goals. The term 'sustainability' was, initially, clarified through empirical examples and applications of everyday life. It was then connected with the 13th SDG goal, namely, the cognitive area of climate study and action.

The third stage of the scenario was related to the exploitation of the educational robot in the teaching process. Following relevant preparation, the teacher introduced ENVIE S50 to children. The movement and playback of audiovisual material by the robot was handled by a corresponding application on the teacher's smart device. According to the educational script, ENVIE S50 chose the particular classroom so as to deliver a crucial message about the evolution of climate change in Iran in 2050. As for the teaching strategy, the main purpose of this stage was to develop the "educational problem" which children would be asked to solve with their stories. The problem was expressed throughout the digital stories of both the robot and Reza. It was about detecting people's responsibilities for worsening climate change and also about taking action through the change of thinking and lifestyle. Reza's descriptions of his country's extremely difficult living conditions were especially aimed at developing empathy in children living in 2021, following the relevant literature review. These are the two indicative texts that were included in the digital stories displayed in the robot's screen, located in its head. The first one was delivered by the robot, and the second one by Reza:

"Good morning guys, my name is ENVIE-S50 and I am a new generation technological robot. I was created in 2048 in a modern digital sustainable development laboratory. My mission is to check up on the achievement of the United Nations' sustainable development goals. I am sure you are aware of these objectives. I know how you understand the importance to have those objectives accomplished for the future of all mankind. I have been programmed in such a way to be able to travel back in time in order to communicate and deliver important data and information to selected people. For this reason, I arrived today in Greece after a back in time journey. This journey lasted exactly 86,400 s. It started in 2050. I'm currying a really crucial message related, in particular, to global warming and climate change ..."

"Hello, mates. I'm Reza and I live in Tehran, Iran. This the year 2050 and I am 12 years old. Envi-S50 informed me about his mission to travel to 2021 to deliver important information about the climate condition of my country and the whole world. I would definitely wish to travel along to get to know each other and learn about the climate of your country, my country and the whole world in 2021. In return, I am recording this message for you. After a brief research on the climate records of your time, I realized that global climate condition was in a logical and tolerable level despite people's concern about their gradual rise. Additionally, looking at photos and videos from my city in early twenties caused me a great surprise. This is because I realized that people were freely walking the streets throughout the whole year, without restrictions and bans on account of burn risk. I can tell you, my friends, that this seems ideal and magical to me. As I speak to you, it's May fifteen, five in the afternoon and the temperature in Tehran is close to 55 Celsius degrees. People can't go out without special uniform nor walk around outside without permission. School was closed due to high temperature and lessons were remotely carried out through computers. We are actually informed whether schools will be open or closed from special weather forecasts ..." 
The fourth stage of the scenario mainly concerned students' storytelling. More specifically, they were asked by the educational robot to think and write down their own stories using the information about the planet's future climate situation. These stories actually highlighted the potential change of their attitude towards climate change global problem. They also reflected the impact of the negative image of the future global climate on their emotional word and their feelings. It was a kind of a solution to the "educational problem" expressed by Reza, their Iranian peer from 2050. The stories were recorded in the robot's memory. According to the scenario, the robot would travel back to the future so as to check whether children's attitude changes could potentially reverse the negative developments of climate change. Thus, a general teaching objective was fulfilled, where people could form their future through active citizenship.

In the final stage, children were asked to complete a worksheet based on the knowledge they came across through the scenario activities. It had, mainly, to do with the understanding of the terms sustainability and climate change, together with their effects on people's lives. In terms of empathy development, they were also asked to draw something for Reza together with a small written message for him. Additionally, the completion of an evaluative rubric regarding the degree of involvement and the level of children's empathy was completed by teachers at this stage. The rubric mainly concerned stages C, D and E. It was developed by the research team using a Likert scale model (Figure 6). The rubric was chosen because it is a useful grading tool which adds reliability and validity to the observation results. It is often used to increase transparency in school projects and to decrease subjectivity [34]. A well-designed rubric is one that helps educators to judge students' work effectively, and to also keep records on attitude change incidents throughout teaching activities.

\begin{tabular}{|l|l|l|l|l|l|}
\hline Child's name: & \multicolumn{5}{|l|}{} \\
\hline Stage C & $\begin{array}{l}\text { Strong } \\
\text { Obvious }\end{array}$ & Obvious & Neutral & Poor & $\begin{array}{l}\text { Strong } \\
\text { Poor }\end{array}$ \\
\hline Use of emotional words and phrases & & & & & \\
\hline Change in emotional state & & & & & \\
\hline Self-awareness of empathy development & & & & & \\
\hline Stage D & & & & & \\
\hline Use of emotional words and phrases & & & & & \\
\hline Use of emotional words and phrases in written stories & & & & & \\
\hline Change in emotional state & & & & & \\
\hline Self-awareness of empathy development & & & & & \\
\hline Stage E & & & & & \\
\hline Use of emotional words and phrases & & & & \\
\hline
\end{tabular}

Figure 6. The evaluative rubric regarding the development of children's empathy.

\section{Research Methodology}

This pilot research project was conducted in a primary school in Athens, Greece. In particular, two sixth grade classes took part, with a sum of 50 students. Children of both classes attended the elementary curriculum, and no serious learning difficulties were recorded. All children were excellent native speakers. The project was piloted with groups of 10 students. Each group volunteered for $3 \mathrm{~h}$ in total, and the whole project lasted three days. Naturalistic observation was the method adapted by the research group. This type of observation was appropriate because participants' behaviors were studied in natural surroundings. Additionally, there were no predetermined behavioral codes established either by researchers or teachers. Instead, rigorous notes on children's performance during project activities were taken and all data were coded later. In such qualitative studies, researchers actively participate or observe the teaching intervention and complete an observation journal during or right after the process (in order to not forget details which may be significant). Then, the notes are coded and interpreted in order to extract conclusions. This was the case in this study. 
Institutional approval was obtained for this study. All project stages were recorded so as to make the validity of the observation findings more accurate and valid. Teachers of two classes participated in the study, helping in the collection of the data. They were also interviewed at the beginning in terms of shaping the empathy level of each student. Thus, data to evaluate the potential of the teaching strategy related to empathy development were obtained from student self-assessments of empathy and reflective writings throughout the school year. Taking children's age into account, equally important were the teachers' evaluation of the empathy level of each child, along with their yearly development. Finally, teachers were responsible for keeping records on the evaluative rubric during the whole procedure. Such rubrics which rely on observations represent an objective, although justified, constituent, which is very common in qualitative research.

Children's written stories from the project activities were read and coded independently by two members of the research group with no affiliation to the previous level of empathy of participants. Coders were also blind to any information about students because any identifying and other kind of information was deleted from the reflections. Coding occurred after the end of all group work. Apart from the written stories, coders determined how many times students experienced a change in their level of empathy across the recordings. These changes were noted either through relevant emotional phrases, expressed written or orally by students, or when the coders noted a change in their emotional state through their comments and attitude throughout the activities. They also noted phrases and dialogues which indicated that students became more aware of their own empathetic development.

\section{Results and Discussion}

The rubrics and recordings debriefing highlighted the high degree of empathy development in children, especially with regard to Reza's personal history. The expression of emotions both in the stories about their attitude change and the messages to him was remarkable (Figure 7). More specifically the highest percentages occurred in stages D and E, where the "obvious" indicator reached a total average of $60 \%$ and "obvious strong" in $20 \%$.

Stage $C$

Use of emotional words and phrases

Change in emotional state

Self-awareness of empathy development

Stage $D$

Use of emotional words and phrases

Use of emotional words and phrases in written stories

Change in emotional state

Self-awareness of empathy development

Stage $E$

Use of emotional words and phrases

Use of emotional words and phrases in written messages

Expression of emotions in drawing

Self-awareness of empathy development

\begin{tabular}{|lllll|}
\hline S.O. & Ob. & N. & Po. & S. Po. \\
\hline $4 \%$ & $16 \%$ & $52 \%$ & $20 \%$ & $8 \%$ \\
\hline $12 \%$ & $32 \%$ & $46 \%$ & $8 \%$ & $2 \%$ \\
\hline $4 \%$ & $4 \%$ & $4 \%$ & $76 \%$ & $12 \%$ \\
\hline & & & & \\
\hline $12 \%$ & $64 \%$ & $16 \%$ & $6 \%$ & $2 \%$ \\
\hline $42 \%$ & $38 \%$ & $10 \%$ & $6 \%$ & $4 \%$ \\
\hline $30 \%$ & $62 \%$ & $4 \%$ & $2 \%$ & $2 \%$ \\
\hline $20 \%$ & $30 \%$ & $40 \%$ & $5 \%$ & $5 \%$ \\
\hline & & & & \\
\hline $18 \%$ & $68 \%$ & $6 \%$ & $6 \%$ & $6 \%$ \\
\hline $14 \%$ & $64 \%$ & $14 \%$ & $6 \%$ & $2 \%$ \\
\hline $6 \%$ & $30 \%$ & $38 \%$ & $20 \%$ & $6 \%$ \\
\hline $12 \%$ & $48 \%$ & $24 \%$ & $10 \%$ & $6 \%$ \\
\hline
\end{tabular}

Figure 7. The percentages resulting from debriefing the rubric.

At stage $C$, the students did not express their feelings through corresponding words and phrases to a large extent. Similarly, their emotional state remained stable, according to the researchers' observation. For this reason, the 'neutral' category had the highest proportion, i.e., $52 \%$ and $46 \%$, respectively. This is a reasonable and expected research finding, because students at this age need time to emotionally process the information received and express themselves in response.

It is still considered particularly important to note that at this stage, students did not seem to understand the change in their emotional state while the educational robot and Reza presented the negative scientific data and the difficult daily living of people in 2050. Most students (88\%) reacted cautiously to listening to digital stories, taking a rational stance. This percentage was considered unexpectedly high in view of the large difference 
with the percentages in stages $\mathrm{D}$ and $\mathrm{E}$. It therefore confirmed the tendency of children not to change their feelings easily and quickly, but to process them internally and to externalize them on some occasions, such as through the work assigned to them by the research team.

In stage $\mathrm{D}$, the percentages clearly indicated both the change in emotional state and the understanding of this change by students themselves. A total of $76 \%$ of them used spoken words and expressions that manifested feelings. At the same time, $80 \%$ incorporated these expressions into written stories. Obvious or very obvious changes in emotional state were recorded in a staggering $92 \%$ of participants, although only $50 \%$ of children themselves seemed to perceive that they had been emotionally affected. Consequently, emotional involvement in the stage is significant, creating a noticeable change from the previous stage.

Similar results occurred at stage $\mathrm{E}$, as far as the use of oral emotional expressions was concerned. In the written stories, i.e., the personal messages to Reza, the use of emotional expressions was less evident than in the written stories in stage D, but overall, students continued to show empathy for his difficult living conditions. Less obvious was the expression of emotions in the drawings. This came as a small surprise in relation to the research forecasts. On the one hand, it could be interpreted as due to the age of the students; on the other hand, by the "emotional fatigue" caused by the written stories.

Finally, after the teaching activities of the project, it was attempted to capture the development of empathy for each student individually in comparison with the degree of empathy in previous school activities, without the use of the educational robot or another form of educational technology. A five-point scale was used. Children's teachers were asked to set the grade for each student before they were even informed about the project with the educational robot. They were also asked to describe the criteria by which they decided on this scoring. After the implementation of the project, they were asked to re-rate the students on the same criteria, evaluating empathetic development. Once again, the results for the 50 students, shown in Figure 8, demonstrate the significant impact of this project on the development of empathy. Most students exhibited an increase of one to two points, whereas there were very few who increased by less than one unit or remained stagnant. Although this measurement is empirical and therefore less valid, it is of great interest because it reflects the opinion of teachers who are better aware of the characteristics of students and their previous levels of empathy.

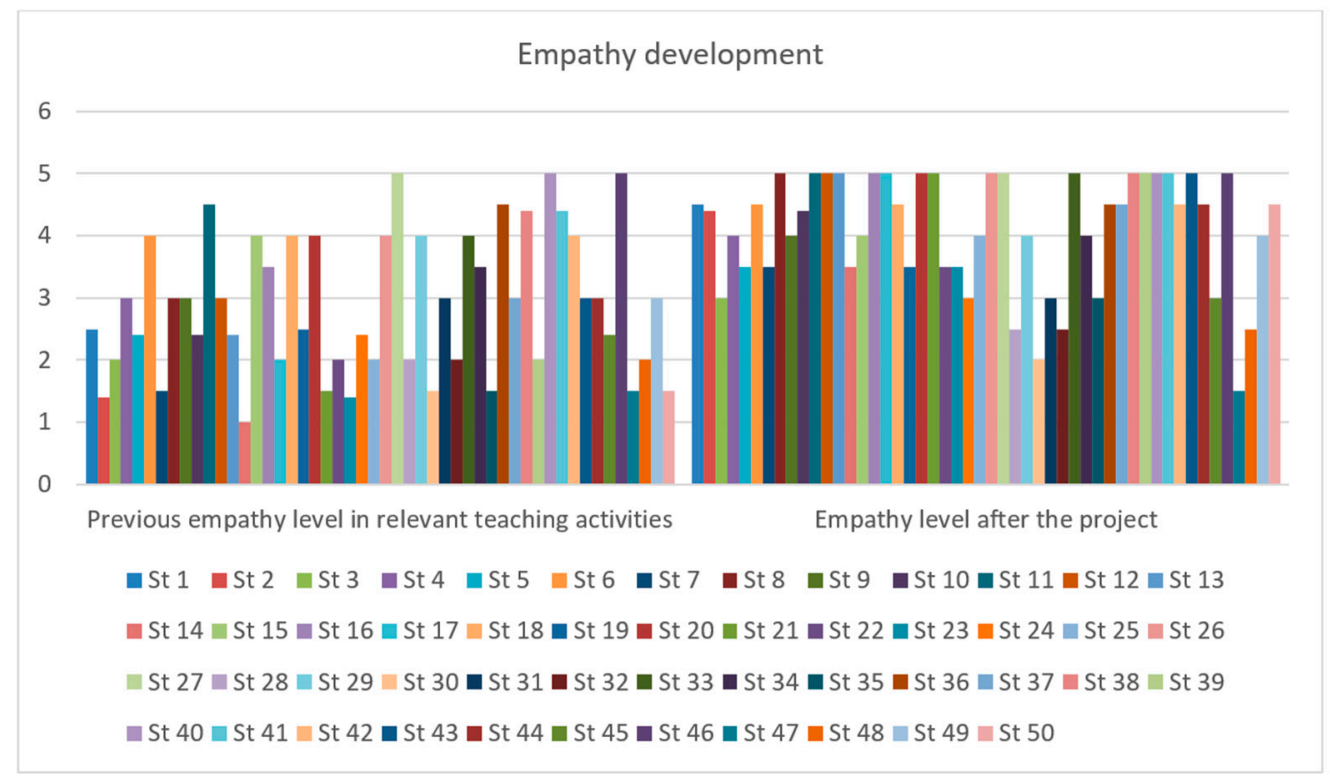

Figure 8. Comparative representation of 50 students' empathy levels. 
Moreover, the fact that this project's activities were mainly presented and carried out by the educational robot and Reza contributed to the development of an immediate and comfortable climate in relation to traditional teaching practice where this role belongs to the teacher. This leads to the conclusion that the development of empathy in school teaching is stronger in a differentiated context than standard, usual practice.

\section{Conclusions}

Measuring children's levels of empathy and the factors that influence them is a particularly difficult issue. Naturalistic observation by members of the research team and by teachers at the school was chosen as the research method because children functioned independently, without coming into contact with any rubrics or other measurement tool. The research results of the observation and rubrics completed by the researchers were varied enough and gave the opportunity to compare and synthesize in order to draw as many objective conclusions as possible.

The alternation of emotions of the children was intense and evident, and all researchers observed responses of the children as an evolution of the educational scenario. The robot's programming contributed to this by clearly highlighting the educational information. This programming was performed through a relevant application on smart devices developed by the research team. Implementation has made a key contribution to the flexibility of this scenario. Specifically, it gave researchers the ability to adjust the view of the videos on the

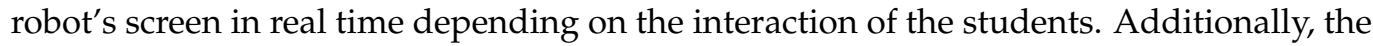
robot's programmed movements gave it anthropomorphic characteristics and contributed to the immediacy of the messages of Envi-S50 and Reza.

The researchers' conclusions about the development of children's empathy and the effectiveness of programming on the robot were complemented and enriched with the pre-existing knowledge of teachers. Teachers' comments were certainly more complete but more subjective. The teachers' opinions on the presence of the robot were universally positive, because everyone recognized the successful completion of the scenario at a technical and educational level. In addition, the comparative juxtaposition of the pre-existing image of the level of empathy of children with this project highlighted the development of empathy in the majority of children.

At the same time, the presence of the robot increased the interest and participation of children and also facilitated the research process. Its technical characteristics, in particular, have been instrumental in the rapid and effective implementation of the activities. The ability to project multimedia material on the robot's screen and the children's interaction with it offered immediacy and flexibility. The presentation of information and the formulation of the educational problem were carried out by the robot itself, which significantly differentiated it from traditional school practice, creating a greater teaching interest in children.

Author Contributions: Methodology, D.Z., D.R., T.B. and M.D.; software, D.Z. and M.D.; validation, D.R. and T.B.; data curation, D.R.; writing-original draft preparation, D.Z., D.R., T.B. and M.D.; writing—review and editing, D.Z., D.R., T.B. and M.D.; supervision, T.B. and M.D.; funding acquisition, D.Z. All authors have read and agreed to the published version of the manuscript.

Funding: This research has been implemented in the framework of the Action "Business Enhancement for Research projects" and co-financed by the European Union and national resources through the B.P. WESTERN GREECE 2014-2020 (project code: DEP5-0019433).

Institutional Review Board Statement: Real teaching settings within the school's official curriculum by the teaches of the specific school, one of which is a member of the authoring/research team. This study falls under the category in which teachers reported upon their in-class intervention and thus no humans are identifiable or directly involved by providing personal information of any kind or being affected by the study in any way, so as to require such approval according to the directives of the UOWM Ethical committee. 
Informed Consent Statement: Informed consent was obtained from all subjects involved in the study.

Data Availability Statement: Publicly not available nor exploitable by other researchers so as to be shared.

Conflicts of Interest: The authors declare no conflict of interest.

\section{References}

1. Yang, Y.; Long, Y.; Sun, D.; Van Aalst, J.; Cheng, S. Fostering students' creativity via educational robotics: An investigation of teachers' pedagogical practices based on teacher interviews. Br. J. Educ. Technol. 2020, 51, 1826-1842. [CrossRef]

2. Massaty, M.H.; Budiyanto, C.W.; Tamrin, A. Revisiting the roles of educational robotics in improving learners' computational thinking skills and their positive behaviour. J. Phys. Conf. Ser. 2020, 1511, 012088. [CrossRef]

3. Ewin, N.; Chugh, R.; Muurlink, O.; Jarvis, J.; Luck, J. Empathy of Project Management Students and Why It Matters. Procedia Comput. Sci. 2021, 181, 503-510. [CrossRef]

4. Berliner, R.; Tracy, L.M. Review of research: Promoting empathy development in the early childhood and elementary classroom: April Bedford and Renée Casbergue, editors. Child. Educ. 2015, 91, 57-64. [CrossRef]

5. Wang, M.; Wang, J.; Deng, X.; Chen, W. Why are empathic children more liked by peers? The mediating roles of prosocial and aggressive behaviors. Pers. Individ. Differ. 2019, 144, 19-23. [CrossRef]

6. O'Conner, R.; De Feyter, J.; Carr, A.; Luo, J.L.; Romm, H. A Review of the Literature on Social and Emotional Learning for Students Ages 3-8: Teacher and Classroom Strategies That Contribute to Social and Emotional Learning (Part 3 of 4). REL 2017-247. Reg. Educ. Lab. Mid-Atl. 2017. Available online: https://files.eric.ed.gov/fulltext/ED572721.pdf (accessed on 9 September 2021).

7. Ratka, A. Empathy and the development of affective skills. Am. J. Pharm. Educ. 2018, 82, 7192. [CrossRef]

8. Lee, J.; Lee, Y.; Kim, M.H. Effects of Empathy-based Learning in Elementary Social Studies. Asia-Pac. Educ. Res. 2018, $27,509-521$. [CrossRef]

9. UNESCO/UNEP. Climate change starter's guidebook. In An Issues Guide for Education Planners and Practitioners; United Nations Educational: Paris, France, 2011.

10. European Commission. Climate Change Consequences. Available online: https://ec.europa.eu/clima/change/consequences_en (accessed on 20 May 2021).

11. Akos, P. Building empathic skills in elementary school children through group work. J. Spec. Group Work 2000, 25, 214-223. [CrossRef]

12. Coll, M.-P.; Viding, E.; Rütgen, M.; Silani, G.; Lamm, C.; Catmur, C.; Bird, G. Are we really measuring empathy? Proposal for a new measurement framework. Neurosci. Biobehav. Rev. 2017, 83, 132-139. [CrossRef]

13. Feshbach, N.D. Empathy in Children: Some Theoretical and Empirical Considerations. Couns. Psychol. 1975, 5, 25-30. [CrossRef]

14. Hoffman, M.L. Toward a Comprehensive Empathy-Based Theory of Prosocial Moral Development; American Psychological Association: Washington, DC, USA, 2001.

15. Jennings, P.A.; Mark, T.G. The prosocial classroom: Teacher social and emotional competence in relation to student and classroom outcomes. Rev. Educ. Res. 2009, 79, 491-525. [CrossRef]

16. Koopman, E.M.E.; Frank, H. Effects of literature on empathy and self-reflection: A theoretical-empirical framework. J. Lit. Theory 2015, 9, 79-111. [CrossRef]

17. Brooks, S. Historical empathy in the social studies classroom: A review of the literature. J. Soc. Stud. Res. 2009, 33, 213-234.

18. De Waal, F. The Age of Empathy: Nature's Lessons for a Kinder Society; Broadway Books: New York, NY, USA, 2010.

19. Bar-On, R.; Richard, H.; Suzanne, F. The Impact of Emotional Intelligence on Performance. Linking Emotional Intelligence and Performance at Work: Current Research Evidence with Individuals and Groups. Psicothema, Spain. 2006, pp. 3-19. Available online: https:/ /books.google.co.jp/books?hl=zh-CN\&lr=\&id=a_OryLZ2W2cC\&oi=fnd\&pg=PA3\&dq=The+impact+of+emotional+ intelligence+on+performance\&ots=vtw5OxYER5\&sig=gg8WN4lhh8EQtkc40NwAXsJ-VXU\#v=onepage\&q\&f=false $($ accessed on 9 September 2021).

20. Malikiosi-Loizou, M. A critical look at empathy. Psychol. J. Hell. Psychol. Soc. 2003, 10, 295-309. (In Greek)

21. Ozbaci, N. Emotional intelligence and family environment. Sos. Bilim. Derg. 2006, 16, 169-175.

22. Orpinas, P.; Arthur, M.H. Creating a positive school climate and developing social competence. In Handbook of Bullying in Schools; Routledge: Washington, DC, USA, 2009; pp. 59-70.

23. Goleman, D. Leadership: The Power of Emotional Intelligence; More Than Sound LLC: Florence, MA, USA, 2021.

24. Stojiljković, S.; Gordana, D.; Blagica, Z. Empathy and teachers' roles. Procedia-Soc. Behav. Sci. 2012, 69, 960-966. [CrossRef]

25. Goroshit, M.; Meriav, H. Teachers' empathy: Can it be predicted by self-efficacy? Teach. Teach. 2016, 22, 805-818. [CrossRef]

26. Ackermann, E. Piaget's Constructivism, Papert's Constructionism: What's the Difference? 2001. Available online: https: //learning.media.mit.edu/content/publications/EA.Piaget/_/Papert (accessed on 10 January 2020).

27. Misirli, A.; Komis, V. Robotics and programming concepts in early childhood education: A conceptual framework for designing educational. In Research on e-Learning and ICT in Education; Karagiannidis, C., Politis, P., Karasavvidis, I., Eds.; Springer: New York, NY, USA, 2014; pp. 99-118. 
28. Jung, S.E.; Won, E. Systematic Review of Research Trends in Robotics Education for Young Children. Sustainability $2018,10,905$. [CrossRef]

29. Toh, L.P.E.; Causo, A.; Tzuo, P.W.; Chen, I.M.; Yeo, S.H. A Review on the Use of Robots in Education and Young Children. Educ. Technol. Soc. 2016, 19, 148-163.

30. Pang, X.; Zhuang, X.; Tang, Z.; Chen, X. Polylactic acid (PLA): Research, development and industrialization. Biotechnol. J. 2010, 5 , 1125-1136. [CrossRef] [PubMed]

31. Vidal, G.; Eyraud, C.-H.; Larose, C.; Lejan, É. Teaching Scientific Evidences of Climate Change to K12: A Key to Reach Social Acceptance of Mitigation and Adaptation Strategies. EGU General Assembly Conference Abstracts; Göttingen, Germany, 2021. Available online: https:/ / meetingorganizer.copernicus.org/EGU21/EGU21-8097.html?pdf (accessed on 9 September 2021).

32. Rousell, D.; Amy, C.-M.-K. A systematic review of climate change education: Giving children and young people a 'voice' and a 'hand' in redressing climate change. Child. Geogr. 2020, 18, 191-208. [CrossRef]

33. Duch, B.J.; Susan, E.G.; Deborah, E.A. The Power of Problem-Based Learning: A Practical How to for Teaching Undergraduate Courses in any Discipline; Stylus Publishing, LLC: Sterling, VA, USA, 2001.

34. Silvestri, L.; Jeffrey, O. Using Rubrics to Increase the Reliability of Assessment in Health Classes. Int. Electron. J. Health Educ. 2006, $9,25-30$. 